\title{
Human as a potential vector of bovine tuberculosis in cattle
}

\author{
Monika Krajewska-Wędzina ${ }^{1, A-D, F \oplus}$, Marcin Weiner ${ }^{2, A, D-E \oplus}{ }^{4}$, Krzysztof Anusz ${ }^{3, A, C, E \oplus}$, \\ Ewa Augustynowicz-Kopeć ${ }^{4, A, E \oplus}$, Marek Lipiec ${ }^{1, C, E \oplus}$, Krzysztof Szulowski ${ }^{1, F \oplus}$ \\ ${ }^{1}$ Department of Microbiology, National Veterinary Research Institute, Puławy, Poland \\ 2 Pope John Paul II State School of Higher Education, Biala Podlaska, Poland \\ ${ }^{3}$ Department of Food Higiene and Public Health Protection, University Of Life Sciences, Warsaw, Poland \\ ${ }^{4}$ Department of Microbiology, National Tuberculosis and Lung Diseases Research Institute, Warsaw, Poland \\ A - Research concept and design, B - Collection and/or assembly of data, C - Data analysis and interpretation, \\ $D$ - Writing the article, E - Critical revision of the article, F - Final approval of article
}

\begin{abstract}
Krajewska-Wędzina M, Weiner M, Anusz K, Augustynowicz-Kopeć E, Lipiec M, Szulowski K. Human as a potential vector of bovine tuberculosis in cattle. Ann Agric Environ Med. 2019; 26(3): 396-399. doi: 10.26444/aaem/102814
\end{abstract}

\section{Abstract}

Introduction and objective. Bovine tuberculosis (bTB, bovine TB) is caused by mycobacteria which are grouped within the MTBC. TB in animals is a highly infectious and progressive disease which can be transmitted to humans. Since 2009, Poland has gained official bTB-free status. Despite the official fact of bTB-free status, a dozen bTB outbreaks are still noted each year. Since 2000 in Poland, every year 1/5 of the national herd is subject to intradermal skin TB testing to control the bTB outbreaks in the cattle population. Application, with 5-year intervals between each government-funded skin test, undoubtedly resulted in financial savings. However it also seems to have caused several adverse and worrying events, e.g. an increase in the number of reactors detected and removed from a single tested herd. The objective of this study was the examination of 898 cattle imputed with bTB infection in Poland between 2008-2012.

Materials and method. The study concerned a potential epidemic outbreak with suspected bTB transmission. 20 cows came from 3 herds in the same county located in the same province in southern Poland.

Results. 134 MTBC strains were identified. In MIRU-VNTR, all isolates showed the same genetic pattern 322532243421232. Based on molecular investigation, the characteristics of $M$. bovis strains isolated from cattle from 3 different herds confirmed the common source of this zoonotic disease.

Conclusions. Although not bacteriologically proven, everything points to the fact that humans were the vector of bovine tuberculosis transmission between herds. This finding confirms transmission between 3 cattle herds in the Małopolskie Province in southern Poland (Podhale). The outbreak of tuberculosis in animals finally compromised public health.

\section{Key words}

bovine tuberculosis, Mycobacterium bovis, epidemiology, zoonosis, mycobacteriology, public health, transmission, tuberculosis

\section{INTRODUCTION}

Bovine tuberculosis (bTB, bovine TB) is an antroponosis and zooantroponosis with the aetiological factors Mycobacterium bovis [1] and Mycobacterium caprae [2]. Both agents are grouped within the Mycobacterium tuberculosis complex (MTBC) [3]. It is worth mentioning that both agents are noted in both animals and human in Poland $[4,5]$.

Bovine TB is subject to control and eradication programmes, which have been performed in many countries with mixed results. Poland has gained official bTB-free status by the European Commission Decision 209/342/EC of 2009. Despite the fact of official bTB-free status, a dozen bTB outbreaks are still noted each year [6]. From 2009 in Poland, every year $1 / 5$ of the national herd is subject to the intradermal skin TB testing to control outbreaks of $M$. bovis in the cattle population. In previous years, $1 / 3$ of the national cattle herd were tested annually. Application, with 5-year intervals between each government-funded skin test, undoubtedly resulted in financial savings. However, it also seems to have caused several adverse and worrying events, e.g. an increase in the

Address for correspondence: Monika Krajewska-Wędzina Department of Microbiology, National Veterinary Research Institute, Puławy, Poland e-mail: monika.krajewska@piwet.pulawy.pl

Received: 09.07.2018; accepted: 14.01.2019; first published: 10.04.2019 number of reactors detected and removed from a single tested herd. In 2012, the average reactor removal was approximately 7 animals from the one given herd, but in 2015 the number had risen to over 12 animals from the herd. In 2017, there were 15 outbreaks of tuberculosis caused by $M$. bovis, and the number of reactors removed from 2 particular herds was 25 for each head count of cattle.

By the end of September 2018, there were 9 confirmed outbreaks of bTB, with the most significant disclosing 127 reactors in a single herd (unpublished data). At the same time, advanced clinical signs of the disease were observed in the removed cattle, which highlighted late generalisation of the process, and extensive lesions outside the respiratory system, e.g. in the liver. Furthermore, in 2015 and 2016, an increase in the number detected was noted in slaughterhouse cases. The infected animals were found during post-mortem examination at the abattoir, rather than during planned skin TB testing. These facts provide strong evidence that the 5-year interval between skin TB tests of the same animal might be too long.

Bovine tuberculosis is a highly infectious and progressive disease. Recently, in central Poland, transmission of tuberculosis from cattle to humans was confirmed (unpublished data). In one agricultural holding, the tuberculosis infection affected a farmer and 21 cattle. The 
man was reported to drink raw milk obtained from his cows. However, he was also exposed to the transmission via droplets excreted by the animals.

In 2016, a systematic review of economic evidence for the eradication and control programmes was defined [7]. Even at the beginning of the 21st century, monitoring and eradication of BTB is difficult. The problem is the reliability of ante-mortem tuberculosis diagnostics in animal [8], and the extensive reservoir of the germ in free-living herds of wild animals $[9,10,11]$. Monitoring of infectious diseases and their control programmes are of immense economic importance to the country and the livestock industry.

\section{MATERIALS AND METHOD}

Material for the microbiological diagnostics was collected post mortem, according the Chief Veterinary Officer Instructions, and comprised chest lymph nodes and lung segments obtained from 898 cattle (Bos taurus). The animals came from 5 Polish regions: south-western, eastern, central, north-western and northern parts of the country. The tissue material was analysed in accordance with the instructions from the Chief Veterinary Officer in order to obtain the precipitate for the cultures on Stonebrinck, Petragnani and Loewenstein-Jensen media. All slants were incubated at $37^{\circ} \mathrm{C}$ for 6 weeks.

The strains grown on Stonebrinck media were preidentified by commercial MGIT TBc Identification Test ${ }^{\oplus}$ (Becton Dickinson), an immunochromatographic assay for detecting MPT64 protein fraction secreted by the MTBC cells during culture [12]. After placing a sample in a testing well, the MPT64 antigen binds to antibodies directed against MPT64, coupled with visualization particles located on the test strip. The antigen-conjugate complex migrates through the test strip reaction area, and is captured by a second specific antibody MPT64 located on the membrane. If the sample contains the antigen MPT64, the labelled particle with colloidal gold produces a colour reaction.

Identification of Mycobacterium tuberculosis complex strains was verified by the GenoType $\mathrm{MTBC}^{\circledast}$ molecular test, which is based on DNA.STRIP technology, and through the analysis of the gyrB gene, polymorphism can identify species belonging to the MTBC. Each test strip contains 3 areas of control: 1) conjugate control (CC) - to check the binding of the conjugate on the strip and the correct reagent reaction, 2) universal control (UC) to detect the presence of the DNA of all mycobacteria and members of the group of gram-positive bacteria with a high $\mathrm{G}+\mathrm{C}$ content, and 3) an MTBC control zone to confirm the presence of bacteria of the Mycobacterium tuberculosis complex in the sample.

Genetic profiles of strains were defined by spoligotyping and MIRU-VNTR genotyping methods. The spoligotyping method (Spacer oligonucleotide typing) detects polymorphism of the chromosomal DR region (Direct Repeat) occurring only in the genome of MTBC [13]. This locus contains a variable number of simple 36-bp DR-sequences, and between them, short (35-41 bp.) unique separating sequences (spacers). The number, position and type of spacer sequences determine the variability of mycobacteria. For the detection of these sections, synthetic oligonucleotide probes are used, which are complementary to 43 spacer sequences identified in M. tuberculosis $\mathrm{H} 37 \mathrm{Rv}$ and M. bovis BCG strains.
In the spoligotyping method, the whole DR region is amplified using primers (Dra - labeled with biotin and $\mathrm{DRb}$ ) complementary to repetitive DR sequences. Biotin labelled PCR products are transferred to a nylon membrane containing covalently-binding oligonucleotides, and then subjected to the hybridization process. By using streptavidinperoxidase conjugate which has an affinity for biotin, the result of hybridization is reflected in the chemiluminescent reaction. In this study, spoligotyping was performed using Isogen ${ }^{\circledast}$ kit (Isogen Bioscience, The Netherlands). The hybridization patterns obtained on photographic film were compared to the profiles registered in the international spoligotype databases www.Mbovis.org [14].

The MIRU-VNTR method (Mycobacterial Interspersed Repetitive Units - Variable Number Tandem Repeat) was based on the analysis of 15 polymorphic microsatellite sequences localized in the genome of mycobacteria [15]. The DNA of each strain were subjected to 15 amplification reactions using 15 primer pairs. PCR products were separated on $2 \%$ agarose gel and analysed under UV light. The results are shown in the form of 15-digit codes, wherein each digit represents the number of the repetitive sequence in MIRUVNTR loci.

\section{RESULTS}

Between 2008-2012, 134 MTBC strains were identified from 898 tissues collected from cattle in Poland, which were subsequently identified as $M$. bovis (103 isolates; 77\%) and M. caprae (31 isolates; $23 \%$ ).

The study concerned a potential epidemic outbreak with suspected bTB transmission in 20 cows from 3 herds in the same county located of the Małopolskie Province in southern Poland. In clinical studies before the liquidation of the animals, none of the cows showed any symptoms suggestive of infection; they were in a generally good condition and well nourished.

However, as a result of pathological examination, calcified tubercles between a few up to $15 \mathrm{~mm}$ in size were exposed in the mediastinal and bronchial lymph nodes in all animals (100\%). Tuberculous lesions with a yellow cheesy mass (10 $20 \mathrm{~mm}$ ) in segments of the lungs occurred in almost half of the examined cows (48\%). 20 strains grown on Stonebrinck media were pre-identified by MGIT TBc Identification Test ${ }^{\oplus}$, and antigen MPT64 was detected in all isolates. This made it possible to group all isolates within MTBC.

Identification of the obtained cultures of bTB mycobacterial strains was performed using the Hain molecular method, which revealed that the strains isolated from the 20 cattle belonged to the Mycobacterium bovis species.

The result of the two-step genotyping analysis of the 20 isolates are shown in Table 1. In 20 cases, the spoligotyping method presented spoligotype pattern SB1559, registered previously in the www.Mbovis.org database. In accordance with the database, this spoligotype was isolated from cattle in 2009 in Italy, and submitted by Beatrice Boniotti. In MIRU-VNTR, all isolates showed the same genetic pattern 322532243421232 . 


\section{DISCUSSION}

Based on molecular investigation, the characteristics of $M$. bovis strains isolated from cattle from 3 different herd, confirmed the common source of this zoonotic disease. Two bTB outbreaks (herd numbers 1 and 2) were located in the same village, but on opposite sides, about one kilometre away from each other. The third herd was located about 10 kilometres away from the first two. Everything was checked in detail and according to the data obtained from the District Veterinary Inspectorate in Nowy Targ. The cows from these three herds did not have any contact with each other and their owners did not trade in cattle in this area. The only common factor between the 3 farms was that their owners were from the same family. The farmers often visited each other, helped in breeding, and had a common pool of seasonal workers. Bovine bacilli were probably transferred by their work clothes stained with dried cow's excretions and secretions.

The bTB outbreak in these 3 herds indicates the need for enhanced biosecurity at cattle holdings. It is strongly indicated, and everything points to the fact that humans were the vector of bTB transmission between the herds.

Why did none of the farmers or members of their families become infected with bTB? The are many possible answers. M. bovis has an exceptionally wide host range when compared with the entire MTBC, but some authors claim that the mechanism of host adaptation in microorganism remains unknown [16]. The risk of MTBC infection in all mammals is strongly correlated with the concentration of infectious portions, exposure time, and primarily with the innate and acquired response. In 2013, according to the European Union summary report on trends and sources of zoonoses, zoonotic agents and food-borne outbreaks, the number of confirmed cases of tuberculosis in humans due to M. bovis (134 cases) decreased in the European Union [17]. M. bovis - induced tuberculosis in 2 Polish patients caused by M. bovis, was described for the first time in 2016 [18]. This is a very small number of $M$. bovis human cases compared with the number of TB patients in Poland and worldwide [19, 20, 21].

M. bovis can easily spread from one cow to another through all body fluids and into the environment. In most cases, tuberculosis in mammals is located within the respiratory system; hence, the most common portal of infection is by droplets nucleus. A less common route of infection in cattle is the alimentary tract, i.e. by eating contaminated feed and drinking contaminated water. Equally important are age and general health, which are closely correlated with the immune system.

Calves can acquire infection from cows through colostrum when the disease process involves the udder and associated lymph nodes [22]. At the beginning of the national eradication programme of tuberculosis in cattle, sporadic cases of infection were known to have occurred intrauterine by the umbilical cord, or during partum. The major source of infection for a newborn calf is the first contact with a sick cow and exchanging breaths; therefore, they need to be separated quickly.

The implementation of modern molecular biology methods and observation of new foci of bovine tuberculosis are fundamental for the strategy aimed at controlling the spread of bTB $[23,24]$. The ability to search for the sources of infection (case detection) is one of the main tasks in bTB eradication.
Free-living animals also play a large role in the spread of bTB in cattle. The pastures are mainly places where common transmission takes place [8]. For example, in the UK, and probably in the Republic of Ireland, the reservoir of $M$. bovis are badgers $[25,26]$. Preliminary studies conducted by Lipiec and others prove that in Poland the badger population is free from bTB infections [27].

Standardization of applied methods enables the comparison of genetic patterns of strains isolated worldwide and track their global spread. The knowledge provided by molecular diagnosis of tuberculosis, complemented by detailed epidemiological investigation, allows the tracking of transmission of tuberculosis in the environment, and hence to protect public health. Consumption of raw milk or non-pasteurised milk products from infected dairy cows is suspected as the source of infection in humans [28]. Summing-up, the outbreak of tuberculosis in the Podhale area of southern Poland compromised public health. This area is famous for local products made from cow's milk, although there is no evidence that the technology for producing smoked cheeses inactivates the tuberculosis bacilli.

\section{CONCLUSIONS}

Tuberculosis is a highly contagious zoonosis. Despite the fact that each germ of MTBC has its own target host, an efficient immune system determines the occurrence of the disease. Although not bacteriologically proven, everything points to the fact that humans were the vector of bovine tuberculosis transmission between herds. The findings obtained in this study confirm transmission between 3 herds of cattle herds in the Małopolskie Province in southern Poland (Podhale). The outbreak of tuberculosis in animals finally compromised public health. Appropriate prevention and biosecurity should be implemented on dairy farms to protect healthy animals.

Table 1. Genotype, host and cattle herd of 20 M. bovis isolates

\begin{tabular}{lccc}
\hline Spoligotype & $\begin{array}{c}\text { MIRU-VNTR } \\
\text { (number of strains) }\end{array}$ & Host & Herd \\
\hline $\begin{array}{l}676772777777600 \\
\text { SB1559' }\end{array}$ & $\begin{array}{c}322532243421232 \\
(12)\end{array}$ & cattle & 1 \\
\hline 676772777777600 & 322532243421232 & cattle & 2 \\
SB1559' & $(7)$ & & \\
\hline 676772777777600 & 322532243421232 & cattle & 3 \\
SB1559' & $(1)$ & & \\
\hline
\end{tabular}

${ }^{1}$ Assigned by www.Mbovis.org

\section{REFERENCES}

1. Karlson AG, Lessel EF. Mycobacterium bovis nom. nov. Int J Syst Evol Microbiol. 1970; 20: 273-282.

2. Aranaz A, Cousins DV, Mateos A, Dominguez L. Elevation of Mycobacterium tuberculosis subsp. caprae Aranaz et al. 1999 to species rank as Mycobacterium caprae comb. nov., sp. nov. Int J Syst Evol Microbiol. 2003; 53: 1785-1789.

3. Rodriguez-Campos S, Smith NH, Boniotti MB and Aranaz A. Overview and phylogeny of Mycobacterium tuberculosis complex organisms: implication for diagnostics and legislation of bovine tuberculosis. Res Vet Sci. 2014; 97: S5-S19. doi: 10.1016/j.rvsc.2014.02.009

4. Krajewska-Wędzina M, Augustynowicz-Kopeć E, Weiner M, Szulowski $K$. Treatment for active tuberculosis in giraffe (Giraffa camelopardalis) in a Zoo and potential consequences for public health - Case report. Ann Agric Environ Med. doi: 10.26444/aaem/75685 
5. Orłowska B, Augustynowicz-Kopeć E, Krajewska M, Zabost A, Welz M, Kaczor S, Anusz K. Mycobacterium caprae transmission to free-living grey wolves (Canis lupus) in the Bieszczady Mountains in Southern Poland. Eur J Wildl Res. 2017; 63(1): 1-5.

6. Augustynowicz-Kopeć E, Krajewska M, Zabost A, Napiórkowska A, Zwolska Z. Characterization of Mycobacterium bovis strains isolated from farm and wild animals in Poland. Bull Vet Inst Pulawy 2011; 55: 381-383.

7. Caminiti A, Pelone F, LaTorre G, De Giusti M, Saulle R, Mannocci A, Sala M, Della Marta U, Scaramozzino P. Control and eradication of tuberculosis in cattle: a systematic review of economic evidence. Vet Rec. 2016; 179(3): 70-75.

8. Anusz K, Orłowska B, Krajewska-Wędzina M, Augustynowicz-Kopeć E, Krzysiak M, Bielecki W, Witkowski L, Welz M, Kita J. Ante-mortem and post-mortem tuberculosis diagnostics in three European Bison (Bison bonasus caucasicus) from the enclosure in Bukowiec in the Bieszczady National Park in Poland. Med Weter. 2017; 73(10): 642-646.

9. Gallagher J, Clifton-Hadley RS. Tuberculosis in badgers; a review of the disease and its significance for other animals. Res Vet Sci. 2000; 69(3): 203-217.

10. Corner LA. The role of wild animal populations in the epidemiology of tuberculosis in domestic animals: how to assess the risk. Vet Microbiol. 2006; 112(2-4): 303-312.

11. Beltrán-Beck B, Ballestros C, Vicente J, de la Fuente J, Gortázar C. Progress in Oral Vaccination against Tuberculosis in Its Main Wildlife Resevoir in Iberia, the Eurasian Wild Boar. Vet Med Int. 2012; doi: $10.1155 / 2012 / 978501$

12. Brent AJ, Mugo D, Musyimi R, Mutiso A, Morpeth S, Levin M, Scott JA. Performance of the MGIT TBc identification test and meta-analysis of MPT64 assays for identification of the Mycobacterium tuberculosis complex in liquid culture. J Clin Microbiol. 2011; 49(12): 4343-4346.

13. Kamerbeek J, Schouls L, Kolk A, van Agterveld M, van Soolingen D, Kuijper S, Bunschoten A, Molhuizen H, Shaw R, Goyal M, van Embden J. Simultaneous detection and strain differentiation of Mycobacterium tuberculosis for diagnosis and epidemiology. J Clin Microbiol. 1997; 35(4): 907-914.

14. Smith NH, Upton P. Naming spoligotype patterns for the RD9-deleted lineage of the Mycobacterium tuberculosis complex; www.Mbovis.org. Infect Genet Evol. 2012; 12(4): 873-876.

15. Supply P, Lesjean S, Savine E, Kremer K, van Soolingen D, Locht C. Automated high-throughput genotyping for study of global epidemiology of Mycobacterium tuberculosis based on mycobacterial interspersed repetitive units. J Clin Microbiol. 2001; 39, 3563-3571.

16. Berg S, Smith NH. Why doesn't bovine tuberculosis transmit between humans? Trends Microbiol. 2014; 22(10): 552-553.
17. Osek J, Wieczorek K. Prevalence of zoonoses in animals and zoonotic agents in food in Europe in 2013. Życie Wet. 2015; 90(4): 210-216.

18. Kozińska M, Zientek J, Augustynowicz-Kopeć E, Zwolska Z, Kozielski J. Transmission of tuberculosis among people living in the border areas of Poland, the Czech Republic, and Slovakia. Pol Arch Med Wewn. 2016; 126(1-2): 32-40.

19. Rowińska-Zakrzewska E, Korzeniewska-Koseła M, AugustynowiczKopeć E, Szturmowicz M. What factors may influence epidemiological situation of tuberculosis in Poland and in the world? Pneumol Alergol Pol. 2016; 84(2): 126-133.

20. Kubica T, Rüsch-Gerdes S, Niemann S. Mycobacterium bovis subsp. caprae caused one-third of human M. bovis - associated tuberculosis cases reported in German between 1999 and 2001. J Clin Microbiol. 2003; 41(7): 3070-3077.

21. Torres-Gonzalez P, Cervera-Hernandez ME, Martinez-Gamboa A, Garcia-Garcia L, Cruz-Hervert LP, Bobadilla-Del Valle M, Poncede Leon A, Sifuentes-Osornio J. Human tuberculosis caused by Mycobacterium bovis: a retrospective comparison with Mycobacterium tuberculosis in a Mexican tertiary care centre, 2000-2015. BMC Infect. Dis. 2016; 16(1): 657.

22. Okolo M. Tuberculosis in apparently healthy milch cows. Microbios. 1992; 69: 105-111.

23. Roring S, Scott A, Brittain D, Walker I, Hewinson G, Neill S, Skuce $R$. Development of variable-number tandem repeat typing of Mycobacterium bovis: comparison of results with those obtained by using existing exact tandem repeats and spoligotyping. J Clin Microbiol. 2002; 40(6): 2126-2133.

24. Hilty M, Diguimbaye C, Schelling E, Baggi F, Tanner M, Zinsstag J. Evaluation of the discriminatory power of variable number tandem repeat (VNTR) typing of Mycobacterium bovis strains. Vet Microbiol. 2005; 109(3-4): 217-222.

25. Smith CM, Downs SH, Mitchell A, Hayward1 AC, Fry H, Le Comber SC. Spatial targeting for bovine tuberculosis control: can the locations of infected cattle be used to find infected badgers? 2015; 10(11): doi: 10.1371/journal.pone.0142710.

26. Byrne AW, Kenny K, Fogarty U, O’Keeffe JJ, More SJ, McGratha G et al. Spatial and temporal analyses of metrics of tuberculosis infection in badgers (Meles meles) from the Republic of Ireland: Trends in apparent prevalence. Prev Vet Med. 2015; 122(3): 345-354.

27. Lipiec M, Nowakowski K, Radulski Ł, Iwaniak W, Ważna A. Badgers as a potential source of bovine tuberculosis - first studies in Poland. Ann Agric Environ Med. doi: 10.26444/aaem/80984.

28. Cvetnic Z, Katalinic-Jankovic V, Sostaric B, Spicic S, Obrovac M, Marjanovic S, Benic M, Kirin BK, Vickovic I. Mycobacterium caprae in cattle and humans in Croatia. Int J Tuberc Lung Dis. 2007; 11(6): $652-658$.

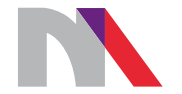

Ministry of Science and Higher Education

Republic of Poland

Generation of the DOI (Digital Object Identifier) - task financed under the agreement No. 618/P-DUN/2019 by the Minister of Science and Higher Education 